\title{
Optimum Gate Location in Injection Mold of Nasal Foreign Body Removal Cover
}

\author{
Shreyas M S \\ M.Tech Student, Department of PG Studies \\ Govt. Tool Room \& Training Centre \\ Mysore, India
}

\begin{abstract}
In plastic injection molding the quality of the plastic part depends on the gate location provided in the mold, hence by providing an optimum gate location the quality of the part can be improved. mold flow analysis is a tool that helps to optimize gate location and predict the flow and also helps to estimate the cycle time of each component which is very much required in mass production of plastic parts and also helps to minimize defects. Mold flow simulation saves time by avoiding trial and error method. The software used in here in this analysis is Autodesk moldflow insight. In this paper right handle of medical part is analyzed by number of iterations to locate optimum gate location and improvise fill time, weld lines, air traps.
\end{abstract}

Keywords - Injection molding, gate locations, mold flow analysis

\section{INTRODUCTION}

Injection molding is process where plastic parts of different shape and size are produced. In this process the molten plastic flows to mold and takes the shape of the cavity after solidifying. Usually there are two types of plastic are used in injection molding they are thermoplastics and thermoset plastics. Building a mold tool is expensive and time consuming so mistakes or alterations in mold causes loss of time, material, and also increases expense. Therefore, here mold flow analysis simulation is used to eliminate trial and error methods, selection of proper gate location and also to improvise parameters which helps in the production of good quality plastic parts.

\section{COMPONENT DETAILS}

Material used for this product ABS (acrylonitrile butadiene styrene) It has got a very good chemical and thermal stability, good dimensional stability and also good electrical property. Its wall thickness is $2 \mathrm{~mm}$, density of the material is $1.02 \mathrm{~g} / \mathrm{cm}^{3}$.

\author{
L G Sannamani \\ HOD, Department of PG Studies \\ Govt. Tool Room \& Training Centre \\ Mysore, India
}

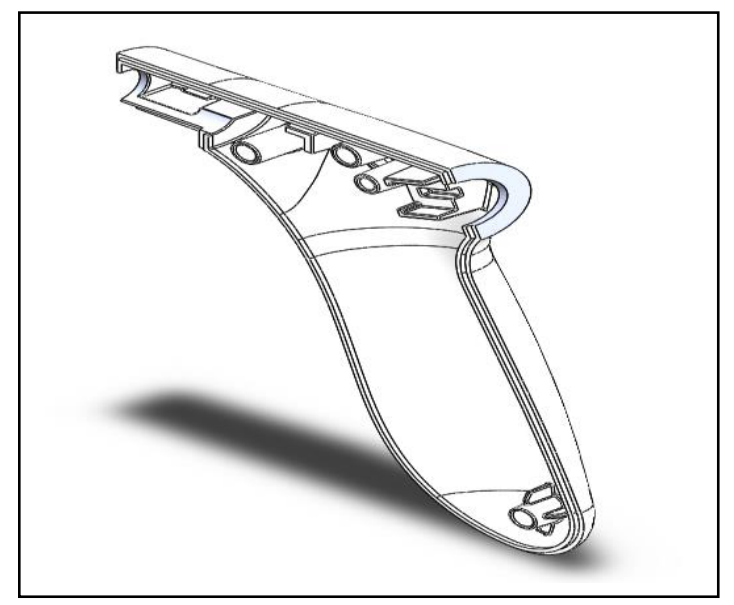

Fig. 1 Part

\section{ANALYSIS}

The main objective is to analyze about the gate position in the injection molding component. While positioning the gate we must consider few factors like the material used, the size of the material, the use of the part and the astatic looks. The parameters like gate position and the number of gates are varied. But here the component which have been selected is small and the need is only one. The software used for this analysis is Autodesk moldflow insight, this software is capable for analysis of fill time, temperature, gate location, weld lines, pressure, warpage and many more

\section{A. Fill time}

Fill time is a time consumed by the thermoplastic material in molten state to flow from injection point to mold cavity. It also analyzes the flow pattern.

\section{B. Air trap}

Air traps are formed when there is no gap for air to escape when thermoplastic material in mold from flows between flow front and the cavity wall

\section{Pressure drops}

Pressure drop is the pressure required to flow the material into the mold cavity until it is completely filled. It also indicates the max pressure required to flow through the different regions 


\section{Temperature flow front}

The temperature flow front shows the temperature of the polymers when it reaches the specified points in the given region

\section{E. Weld lines}

weld lines are created when two flow front meets. Weld line indicates the weakness in the structure

\section{ITERATION}

These iterations are made to find the optimum gate location to produce defect free and a good quality product

\section{A. First iteration}

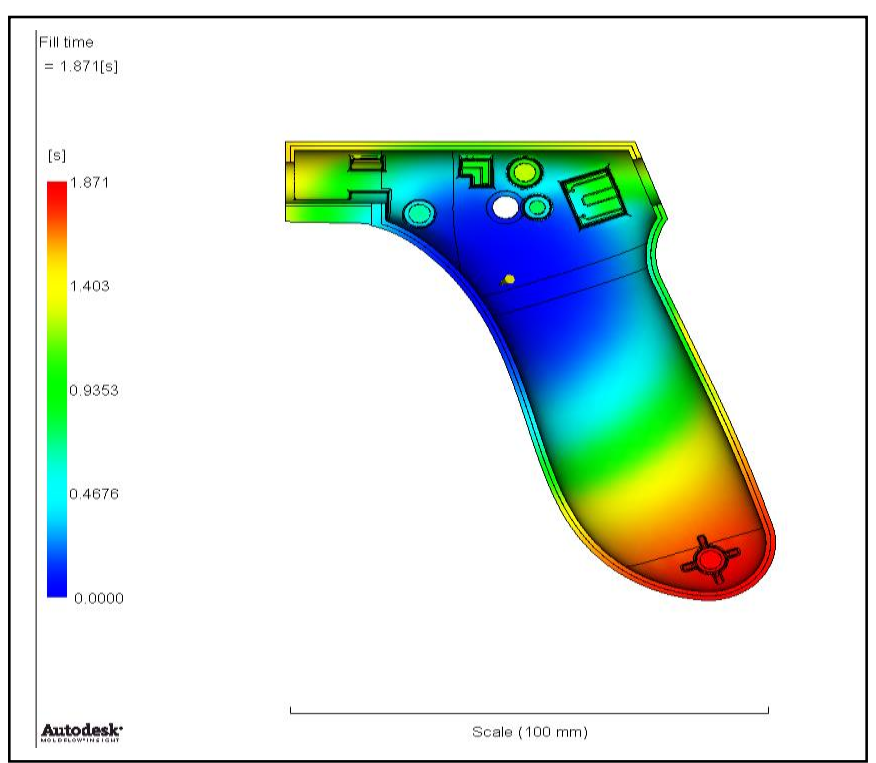

Fig 2.0 Fill time

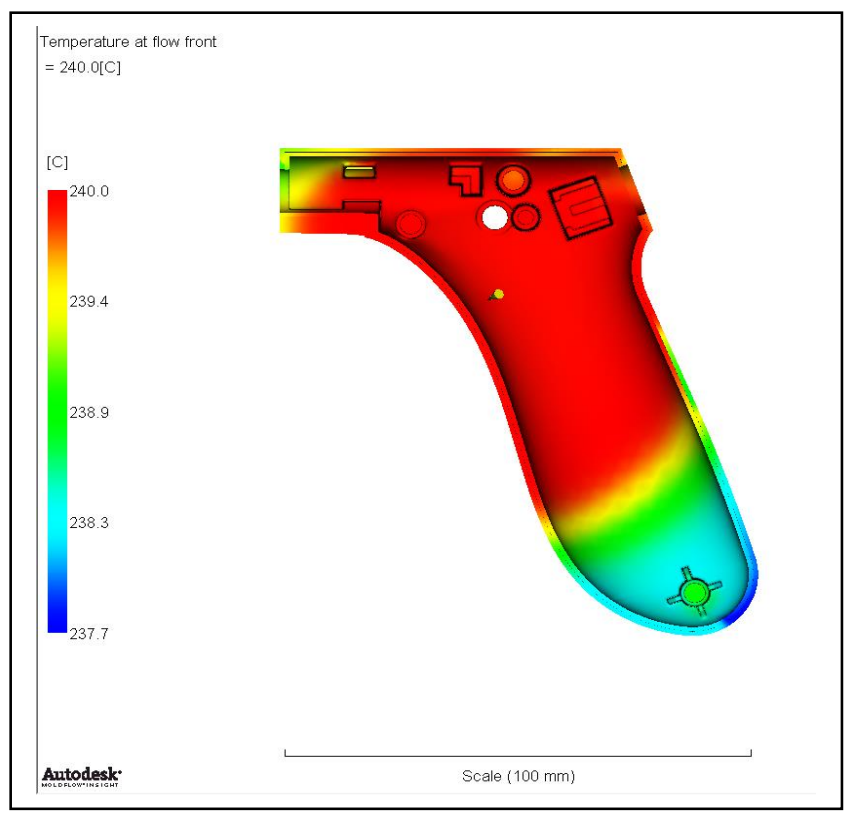

Fig 2.1 Temperature at flow front

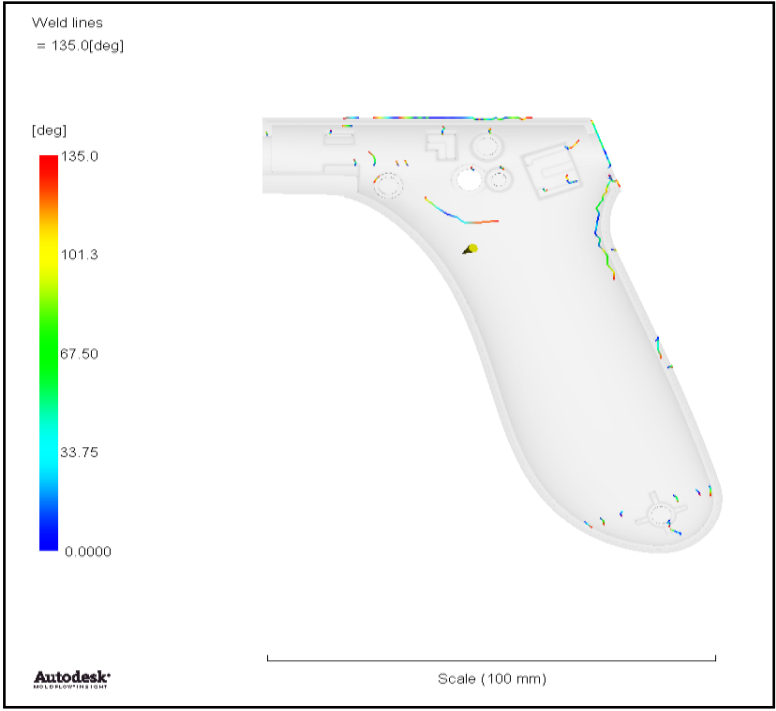

Fig 2.2 Weld lines

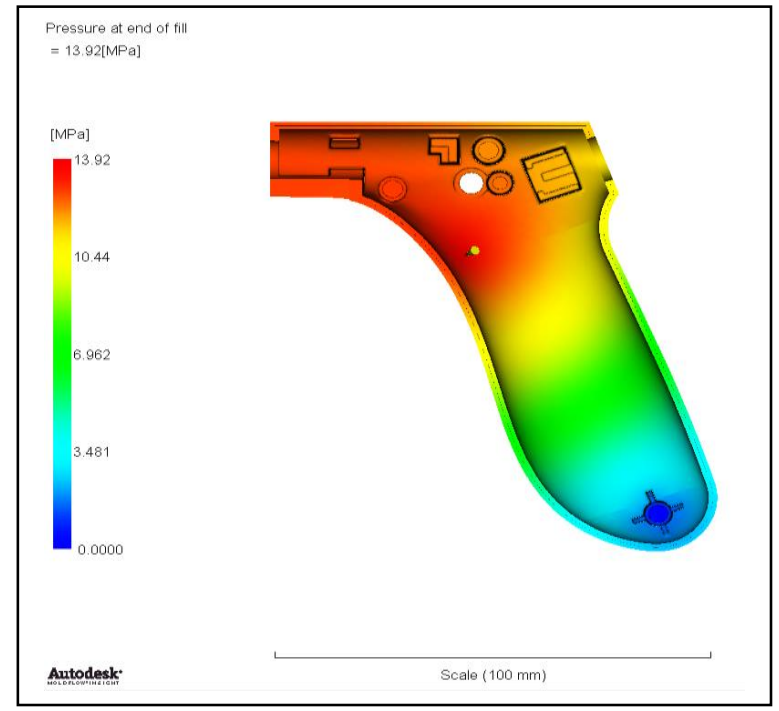

Fig 2.3 Pressure at end of fill

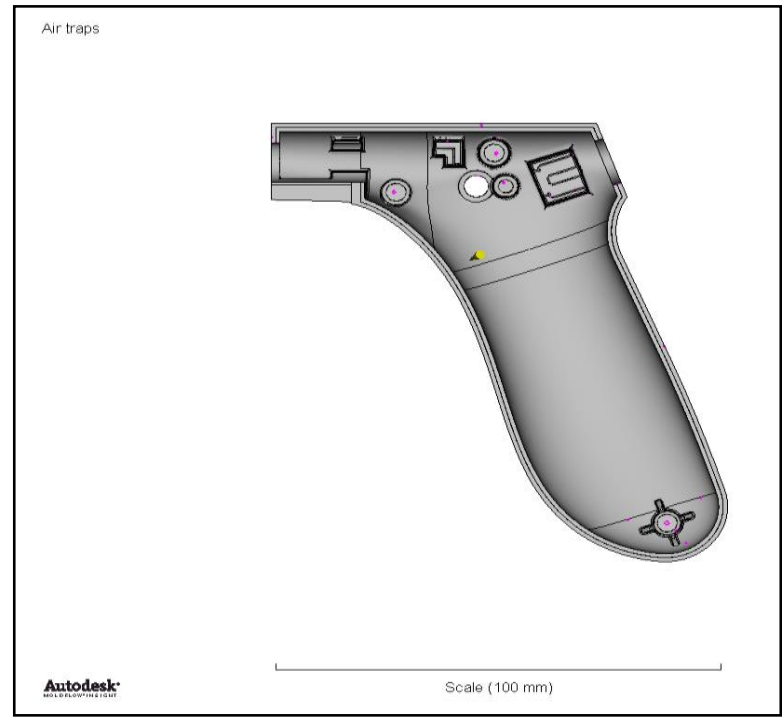

Fig 2.4 Air traps 
Gate position 1, as shown in first iteration the results obtain are

- The fill time achieved is 1.871 achieved.

- The temperature at flow front achieved is $240^{\circ} \mathrm{C}$.

- Weld lines are not numerous hence its accepted.

- $\quad$ Pressure at the end of fill achieved is $13.92 \mathrm{Mpa}$.

- Air traps are not critical.

\section{B. Second iteration}

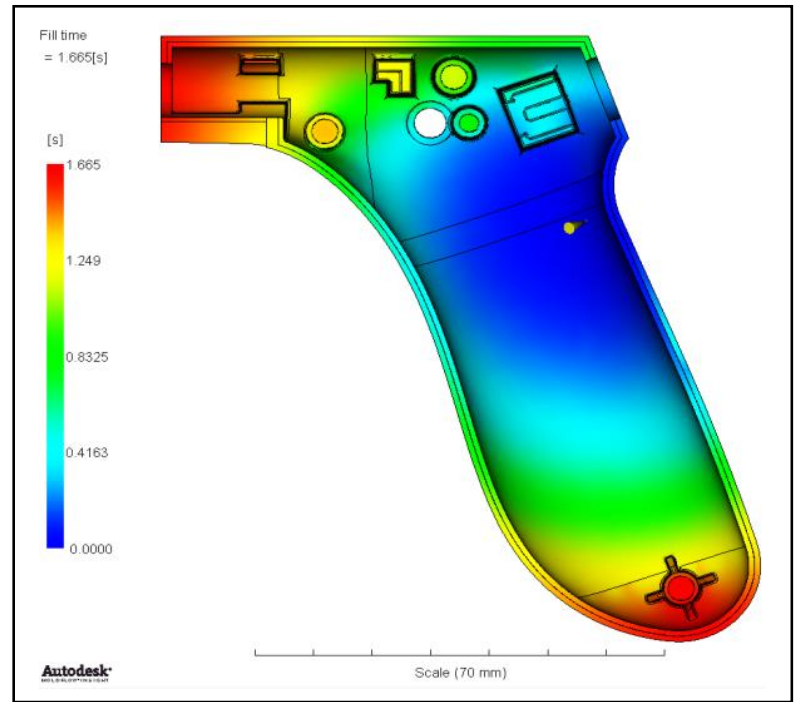

Fig 3.0 Fill time

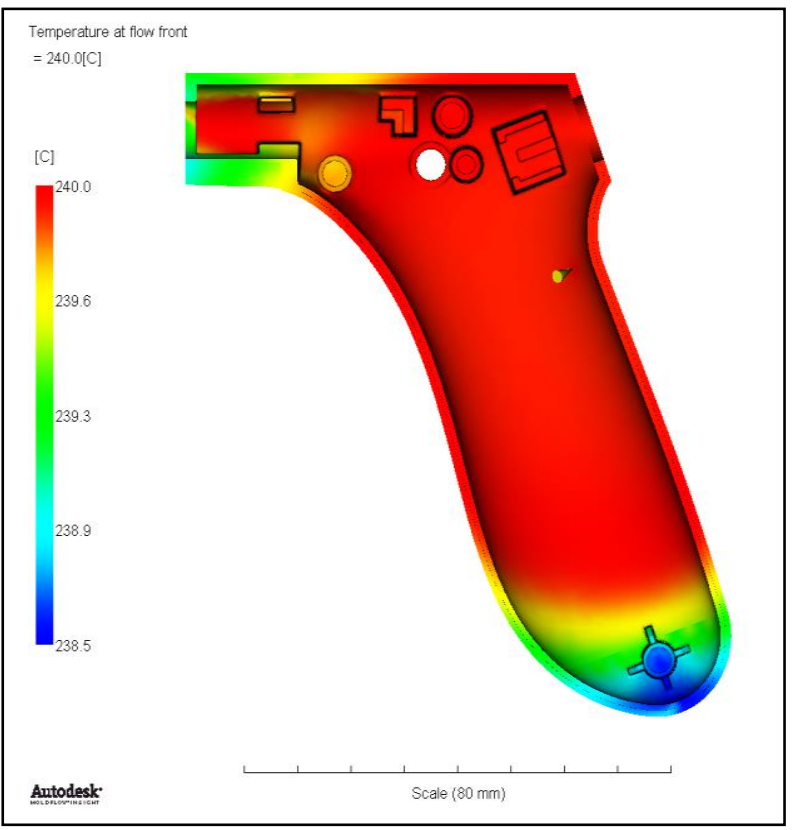

Fig 3.1 Temperature at flow front

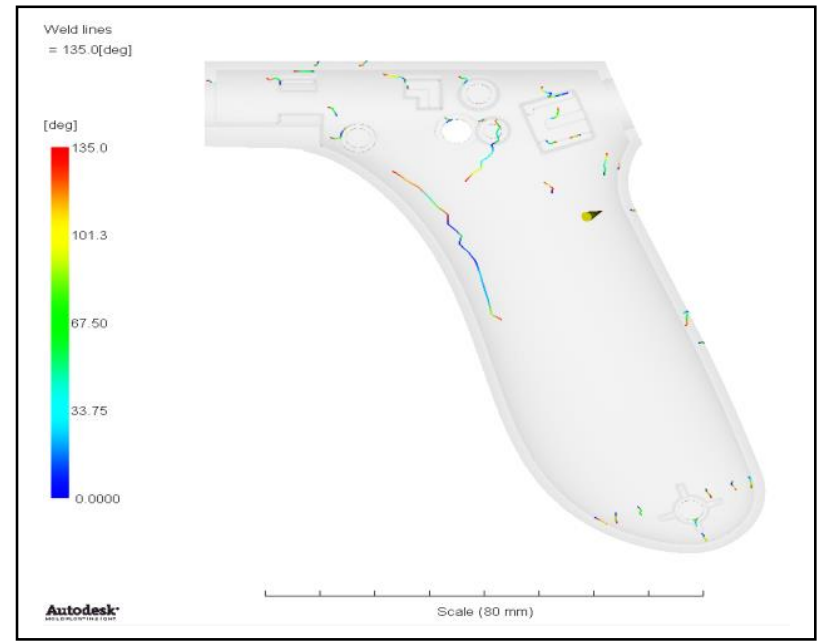

Fig 3.2 Weld lines

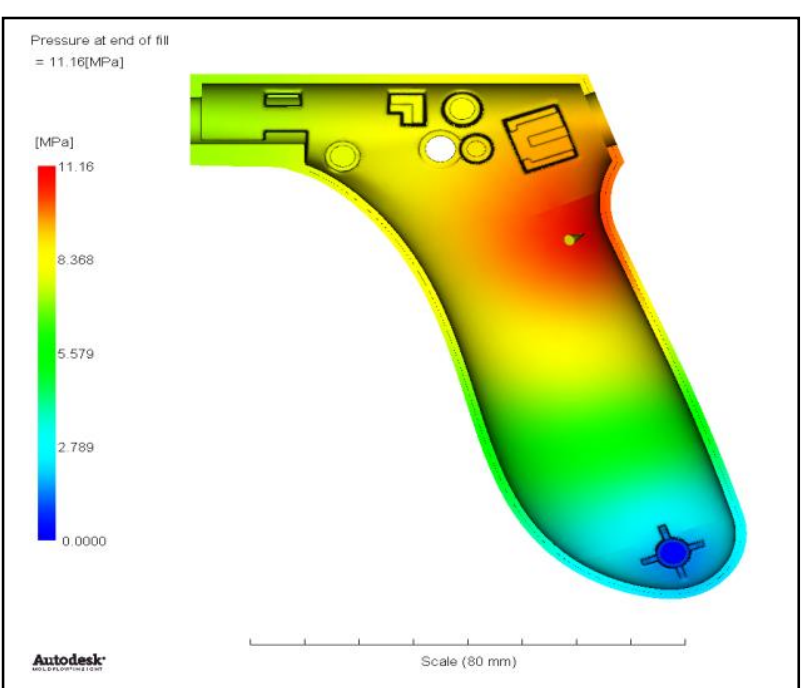

Fig 3.3 Pressure at end of fil

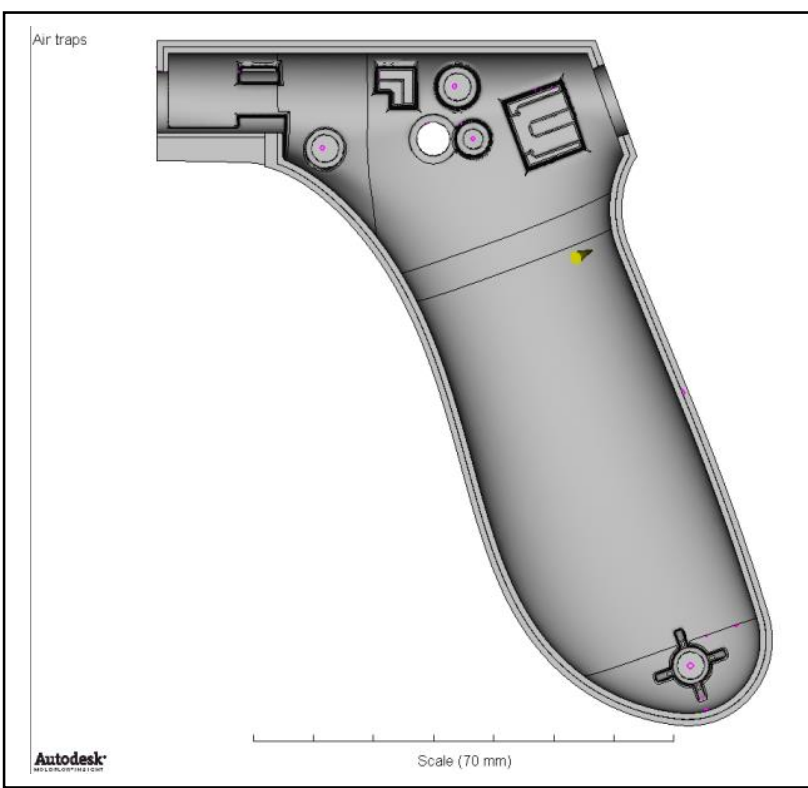

Fig 3.4 Air traps 
Gate position 2, as shown in first iteration the results obtain are

- The fill time achieved is 1.665 achieved.

- The temperature at flow front achieved is $240^{\circ} \mathrm{C}$.

- Weld lines are not numerous hence its accepted.

- Pressure at the end of fill achieved is $11.16 \mathrm{Mpa}$.

- Air traps are not critical

\section{Third iteration}

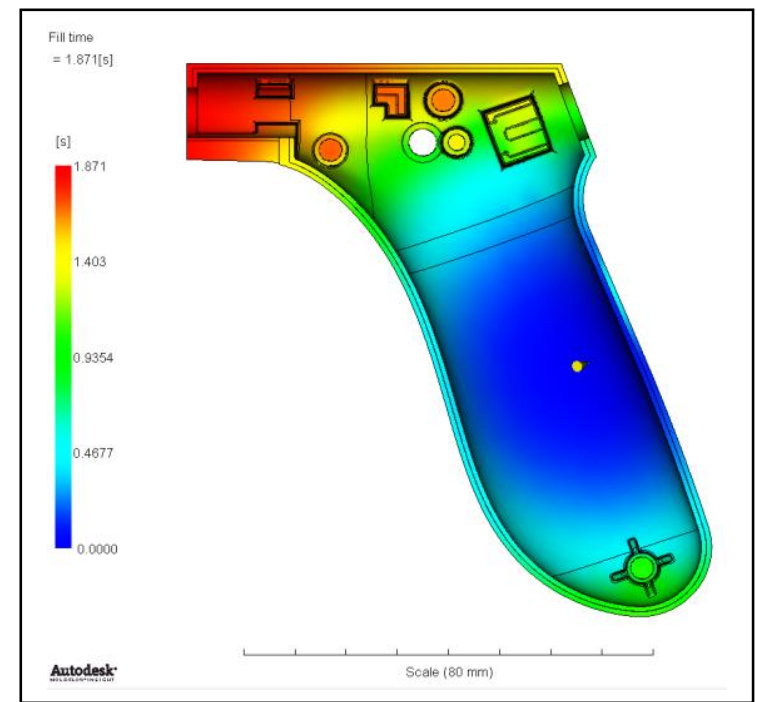

Fig 4.0 fill time

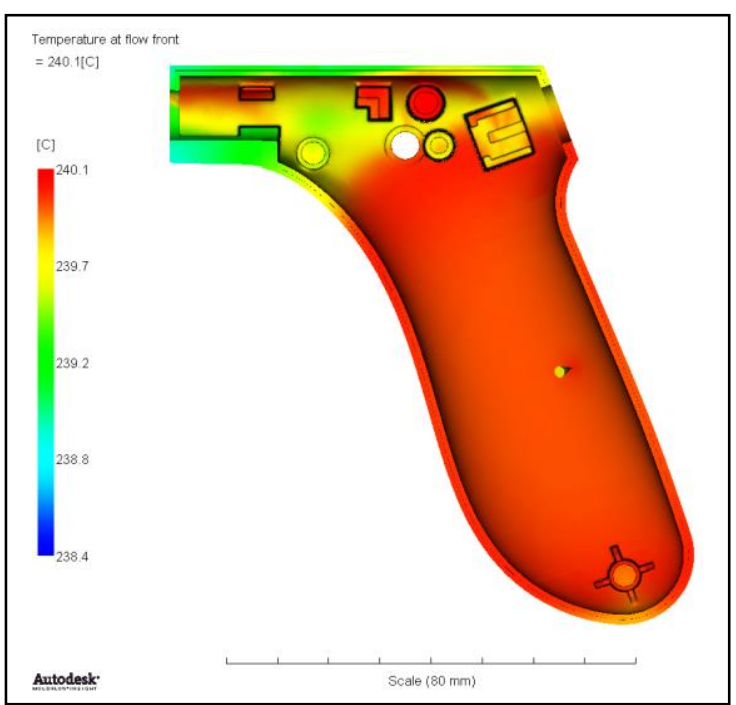

Fig 4.1 Temperature at flow front

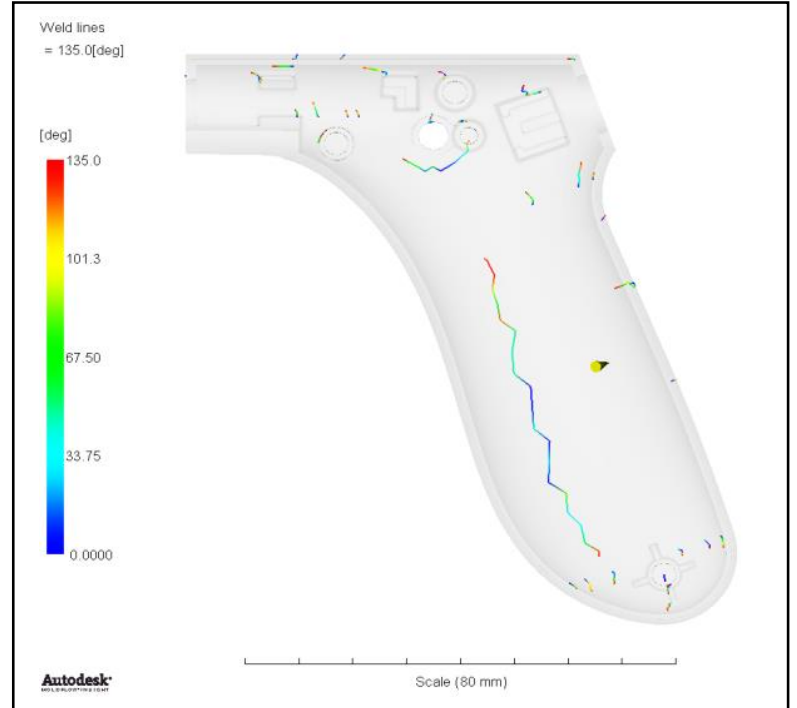

Fig 4.2 Weld lines

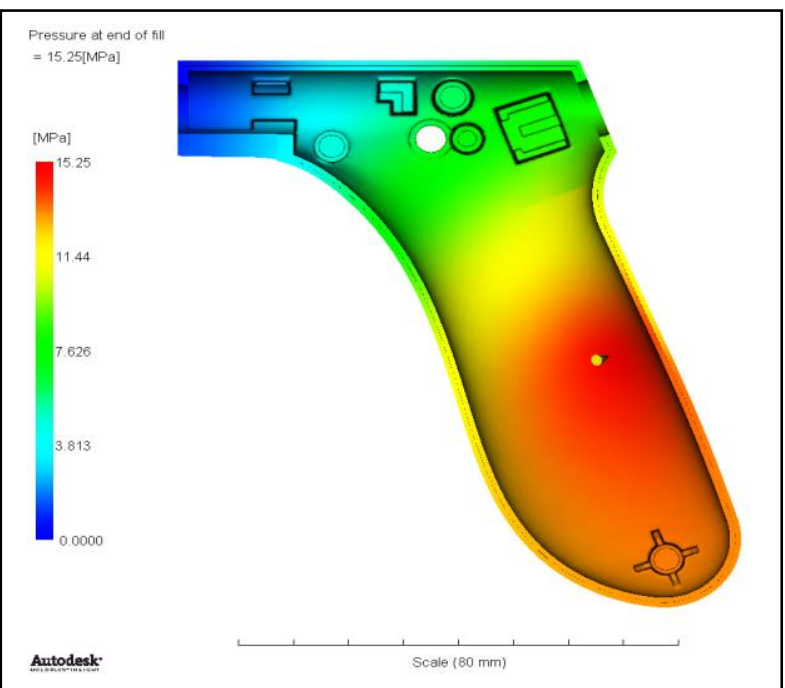

Fig 4.3 Pressure at end of fill

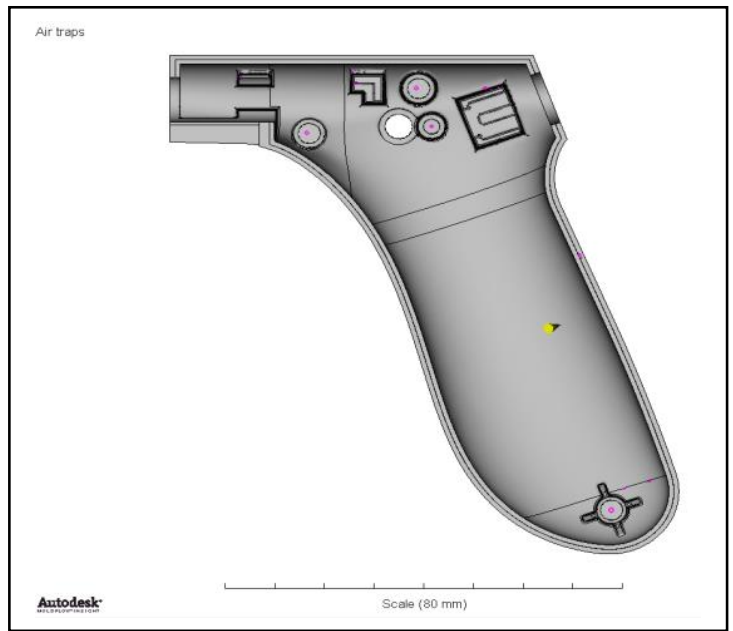

Fig 4.4 Air trap 
Gate position 3, as shown in first iteration the results obtain are

- The fill time achieved is 1.871 achieved.

- The temperature at flow front achieved is $240.1^{\circ} \mathrm{C}$.

- Weld lines more in critical region hence it's not accepted.

- Pressure at the end of fill achieved is $15.25 \mathrm{Mpa}$.

- Air traps are not critical

\section{CONCLUSION}

In this analysis of the component different gate location were consider. In above iterations results gate 3 is not suitable because it has got a greater number of weld lines, shrinkage is more compare other two. In gate 2 its pressure is less compared to gate 1 but air trap and weld lines are more. When gate 1 is selected it gives more quality, less air trap and less weld lines compare to other gates. Air trap can be removed by providing small holes. Hence gate 1 is selected as optimum in this product.

\section{REFERENCES}

[1] RECENT METHODS FOR OPTIMIZATION OF PLASTIC INJECTION MOLDING PROCESS. (Vol. 2(9), 2010,) M. I. Khan, Prof. Harbinder Singh, Professor and Director, Bundel khand Institute of Engineering and Technology, Jhansi, India.

[2] S.R. Pattnaik, D.B. Karunakar, P.K. Jha, "Application of computer simulation for finding optimum gate location in plastic injection moulding process", International Journal of Advanced Engineering Research and Studies E-ISSN2249-8974.

[3] Auto desk Mold-Flow Insight material data warehouse

[4] Sanjay k. Nayak, Pratap Chandra Padhi, Y. Hidayathullah. "Fundamentals of Plastics Mould Design", Tata McGraw Hill Education Private Limited, 2012.

[5] R.G.W. Pye, "An Introduction, and Design Manual for the thermoplastics Industry," 4th Edition, East West Press Pvt. Ltd, New Delhi, 2000.

[6] P.K. Bharti "Recent methods for optimization of plastic injection molding process a retrospective and literature review" International Journal of Engineering Science and Technology Vol. 2(9), 2010, 4540-4554

[7] Manmit Salunke "Injection molding methods design, optimization, Simulation of plastic toy building block by mold Flow analysis" International Journal of Mechanical Engineering and Technology, ISSN 0976 - 6340 (Print) ISSN 0976 - 6359 (Online)Volume 6, Issue 6, June (2015), pp. 33-41 Article ID: 30120150606004.

[8] M. Stanek, D. Manas, M. Manas and O. Suba "Optimization of Injection Molding Process" International Journal Of Mathematics And Computers In Simulation Issue 5, Volume 5, 2011, PP413421

[9] Dominick V Rosato, P.E., Plastics Processing Data Handbook, Chapman and Hall publishers, 1995.

[10] Bryce, D. M., 'Plastic injection molding: Manufacturing process fundamental'. Society of Manufacturing Engineers, (1996). 